\title{
Sealing ability of mineral trioxide aggregate, glass ionomer cement and composite resin when repairing large furcal perforations
}

\section{IN BRIEF}

- Comparison of the sealing properties of three commonly used materials for repair of large perforations.

- Bacteria could penetrate into dentine even distant from the perforation filling.

- Teeth repaired with mineral trioxide aggregate were more resistant to bacterial leakage.

\author{
G. Lodiene, ${ }^{1}$ M. Kleivmyr ${ }^{2}$ E. Bruzell ${ }^{3}$ and D. Ørstavik ${ }^{4}$
}

Objective To evaluate the sealing ability of different repair materials and the pathway of bacterial penetration after closure of large pulp chamber floor perforations. Materials and methods Perforations were made in the furcation area of extracted human molars and sealed with either mineral trioxide aggregate (MTA), glass ionomer cement or resin composite. The bacterial leakage method was used with Enterococcus faecalis as microbial tracer. The time of leakage (in days) was recorded for each specimen. Statistical analysis of bacterial leakage was performed using the survival analysis and pairwise comparison of groups. A p-value less than 0.05 was considered statistically significant. Leaking specimens were prepared and inspected for the presence of bacteria by a scanning electron microscope (SEM). Results The percentage of leaking samples was significantly higher in resin composite than in the other groups and the negative control group $(p<0.05)$. SEM inspection revealed the presence of bacteria in all leaking specimens. Bacteria were observed along the filling-dentine interface as well as in dentinal tubules at some distance from the filling. Conclusions The resin composite material leaked significantly more than the MTA and glass ionomer cements when used to repair large furcation perforations. Bacteria could penetrate into dentine even at a distance from the perforation filling.

\section{INTRODUCTION}

Perforations from the pulp to the surrounding periodontium may occur from resorptive defects, caries or iatrogenic events during endodontic treatment. Perforations create an artificial communication between the root canal system and the supporting tissues of the teeth. ${ }^{1}$

Factors that affect treatment prognosis of perforation repair include the level, location and size of the perforation, the time delay before perforation repair and the material used to seal the perforation. ${ }^{2}$ Biocompatible materials with a short setting time and good sealability should be selected. ${ }^{1}$ The location of the perforation is of crucial importance. Close proximity

"Ph.D. student and Endodontist, Faculty of Odontology, Department of Dental and Oral Pathology, Kaunas University of Medicine, Kaunas, Lithuania; ${ }^{2}$ Endodontist, ${ }^{4}$ Senior Scientist, University of Oslo, Faculty of Dentistry, Institute of Clinical Dentistry, Department of Endodontics, Oslo, Norway; ${ }^{3}$ Professor and Head Department of Endodontics, NIOM - Nordic Institute of Dental Materials, Haslum, Norway

${ }^{*}$ Correspondence to: Mrs Greta Lodiene Email: lodieneg@gmail.com

Online article number E7

Refereed Paper - accepted 17 June 2010

DOI: 10.1038/sj.bdj.2011.198

British Dental Journal 2011; 210: E7 to the gingival sulcus may lead to endodontic-periodontal problems through contamination of the perforation with bacteria from the oral cavity through the sulcus. ${ }^{3}$ It is important that the level of crestal bone and epithelial attachment is taken into consideration. ${ }^{1}$ If the perforation lies coronal of the crestal bone it will be easy to treat and have a good prognosis. Perforations near the crestal bone are susceptible to epithelial migration and rapid pocket formation and treatment of these has a low success rate. ${ }^{4,5}$

Different materials have been used to seal perforations: amalgam, zinc oxide eugenol-based materials, calcium hydroxide, resin monomer, glass-ionomer, MTA, super-EBA etc. ${ }^{2,6,7}$

Important properties of an ideal furcation repair material have been cited as the following: good sealability, ${ }^{8-10}$ biocompatibility, ${ }^{11}$ sufficient antibacterial effect ${ }^{10,12}$ and good handling properties.

Mineral trioxide aggregate (MTA) has received particular attention as a perforation repair material. Several forms of MTA are available on the market, of which ProRoot ${ }^{\circledR}$ MTA Original and ProRoot ${ }^{\circledR}$ MTA tooth-coloured are widely used (Table 1).
These materials differ in their concentrations of aluminium, magnesium and iron compounds. ${ }^{13}$ The tooth-coloured mineral trioxide aggregate lacks the aluminoferrite phase that imparts the grey colour of MTA Original. ${ }^{14}$ Using the bacterial leakage model, no significant difference was observed between the two types of mineral trioxide aggregate in preventing leakage of Fusobacterium nucleatum. ${ }^{15}$ Main et al. ${ }^{16}$ concluded that MTA provided an effective seal for root perforations and showed promise in improving the prognosis of perforated teeth that would otherwise be compromised.

Glass ionomer cements are used in surgical endodontics ${ }^{10,17}$ and they have been advocated for use as a perforation repair material as well. One advantage is its adhesiveness to dentine, and several studies demonstrate its good sealing ability both in vitro ${ }^{2,6,8,18-20}$ and in vivo. ${ }^{21,22}$ However, other studies have shown that resin modified glass ionomer cement showed more microleakage and less sealing ability compared to MTA cement., ${ }^{9,23}$

Rud et al. ${ }^{7}$ investigated retrograde sealing of accidental root perforations with dentine-bonded resin composite 


\begin{tabular}{|c|c|c|c|c|c|}
\hline Name & $\begin{array}{l}\text { Material } \\
\text { group }\end{array}$ & $\begin{array}{l}\text { Setting or } \\
\text { polymerization time }\end{array}$ & Lot number & Manufacturer & Composition according to manufacturer \\
\hline $\begin{array}{l}\text { ProRoot }{ }^{\circledR} \text { MTA } \\
\text { tooth-coloured }\end{array}$ & $\begin{array}{l}\text { Mineral } \\
\text { trioxide aggregate } \\
\text { (tooth-coloured) }\end{array}$ & $4 \mathrm{~h}$ & 05004914 & $\begin{array}{l}\text { DENTSPLY, Tulsa Dental, } \\
\text { Tulsa, OK, USA }\end{array}$ & $\begin{array}{l}\text { Tricalcium silicate, bismuth oxide, dicalcium silicate, } \\
\text { tricalcium aluminate, tetracalcium aluminoferrite, } \\
\text { calcium sulphate dehydrate (gypsum) }\end{array}$ \\
\hline $\begin{array}{l}\text { ProRoot }{ }^{\circledR} \text { MTA } \\
\text { Original }\end{array}$ & $\begin{array}{l}\text { Mineral } \\
\text { trioxide aggregate } \\
\text { (grey) }\end{array}$ & $4 \mathrm{~h}$ & 05003087 & $\begin{array}{l}\text { DENTSPLY, Tulsa Dental, } \\
\text { Tulsa, OK, USA }\end{array}$ & $\begin{array}{l}\text { Tricalcium silicate, bismuth oxide, dicalcium silicate, } \\
\text { tricalcium aluminate, calcium sulphate dehydrate } \\
\text { (gypsum) }\end{array}$ \\
\hline Vitremer & $\begin{array}{l}\text { Resin - based } \\
\text { glass-ionomer } \\
\text { cement }\end{array}$ & $\begin{array}{l}\text { Light polymerization: } \\
40 \mathrm{sec} \text {, setting: } 4 \mathrm{~min}\end{array}$ & 20070227 & $\begin{array}{l}\text { 3M ESPE, Dental Products, } \\
\text { St. Paul, MN, USA }\end{array}$ & $\begin{array}{l}\text { Powder: treated filler: fluoroaluminosilicate glass, } \\
\text { potassium persulphate, ascorbic acid, pigment } \\
\text { Liquid: copolymer of itaconic and acrylic acids, water, } \\
\text { 2- hydroxyethyl methacrylate, photoinitiators } \\
\text { Primer: } 2 \text { - hydroxyethyl methacrylate, ethyl alcohol, } \\
\text { copolymer of itaconic and acrylic acids, photoinitiators }\end{array}$ \\
\hline Retroplast $^{\mathrm{TM}}$ & $\begin{array}{l}\text { Chemically cured } \\
\text { two-component } \\
\text { resin composite }\end{array}$ & $3 \mathrm{~min}$ & 0015 & $\begin{array}{l}\text { Retroplast Trading, } \\
\text { Rørvig, Denmark }\end{array}$ & $\begin{array}{l}\text { BisGMA, TEGDMA, ytterbiumtrifluoride, colloidal } \\
\text { silicon dioxide, ferric oxide and a catalyst system }\end{array}$ \\
\hline
\end{tabular}

and found significantly different healing results depending on the perforation localisation.

According to Tsesis and Fuss ${ }^{24}$ the prognosis of old and large crestal perforations is questionable. The prognosis is also dependent on the prevention or treatment of bacterial infection of the perforation site. In addition, the use of a non-irritating material which seals the perforation will limit periodontal inflammation. ${ }^{1}$

The purpose of this study was 1) to compare the sealing ability of mineral trioxide aggregate (tooth-coloured and grey), resin modified glass ionomer cement and resin composite as large pulp chamber floor perforations repair materials using a bacterial leakage method and 2) to investigate the bacterial leakage pathway with the aid of a scanning electron microscope (SEM).

\section{MATERIALS AND METHODS}

\section{Preparation of the teeth and filling of the perforations}

The study was carried out using 82 extracted human maxillary and mandibular molars. The molars had minimal restorations or caries lesions and non-fused, well-developed roots. The teeth had been stored in saline. Before the initiation of the procedures the teeth were immersed in 5\% sodium hypochlorite for approximately 15 min to remove organic material from the root surfaces. Any remaining surrounding tissue and debris were mechanically removed using a curette. The sodium hypochlorite solution was replaced with saline and changed daily for ten days to wash out residual sodium hypochlorite solution.

Standard access cavities were prepared and the canal orifices were located. The pulp tissue was removed from the chamber by using a spoon excavator. The canals were instrumented using ProTaper ${ }^{\circledR}$ rotary files (Dentsply Maillefer, Ballaigues, Switzerland). Each canal was rinsed with a minimum of $10 \mathrm{~mL}$ saline during and after instrumentation. The teeth were decoronated approximately $3 \mathrm{~mm}$ above the cemento-enamel junction and the roots were horizontally sectioned in the middle third perpendicular to the long axis of the tooth with a high-speed handpiece and a diamond bur using air and water spray.

Furcation perforations of $1 \mathrm{~mm}$ in diameter were created perpendicular to the centre of the pulp chambers floor using ISO 010 round diamond high-speed bur with water coolant. Perforation depth was measured with a micrometer from the pulp chamber floor to the furcation. Data of the measured dentine thickness in the furcation area of the teeth are shown in Table 2. The chamber and perforations were flushed with water from an air/water syringe and dried with oil-free air. Following extensive washing the teeth were stored in distilled water until the filling procedures. The root canals' orifices were obturated with Cavit G (3M ESPE, Dental Products, St. Paul, MN, USA) and stored for $24 \mathrm{~h}$ at $37^{\circ} \mathrm{C}$ and $100 \%$ humidity to allow complete setting. A cotton pellet lightly moistened with saline was placed in the furcation underneath the perforation to simulate clinical conditions, and absorbent points were used to remove excess moisture from the perforation site before filling procedures.

\section{Experimental groups}

The materials for furcation repair (Table 1) were obtained from manufacturers or local dealers. The teeth were randomly divided into four experimental groups of 15 teeth each. Ten teeth were used as negative controls and 12 teeth as positive controls. The groups and material procedures were as follows:

\section{Group 1}

Mineral trioxide aggregate, tooth-coloured (ProRoot ${ }^{\circledR}$ MTA, tooth-coloured). 1 g of powder was mixed with $0.35 \mathrm{~mL}$ of liquid according to the manufacturer's instructions. The material was shaped and formed with MTA Pellet block, placed in the perforation with a carver for MTA block and condensed with an endodontic plugger. A cotton pellet moistened with sterile water was placed in the pulp chamber against MTA.

\section{Group 2}

Mineral trioxide aggregate, grey (ProRoot ${ }^{\circledR}$ MTA, Original). The mixing and filling procedures were as for Group 1.

\section{Group 3}

Resin-modified glass-ionomer cement (Vitremer). Before application of the glass ionomer cement, the dentine was treated with Vitremer primer for $30 \mathrm{sec}$ 
followed by light-induced polymerisation for 20 sec. Vitremer powder and liquid were mixed following the manufacturer's instructions. The mixed cement was placed in the perforation and compacted with endodontic plugger. The surface was polymerised for 40 sec using a dental polymerization lamp "Curing light XL 3,000” (3M ESPE, Dental Products, St. Paul, MN, USA).

\section{Group 4}

Resin composite (Retroplast ${ }^{\mathrm{TM}}$ ). The perforations were treated with EDTA gel for 20 sec. An Adper Scotchbond multi-purpose adhesive system (3M ESPE, Dental Products, St. Paul, MN, USA) was then applied with paper point for another $20 \mathrm{sec}$. Equal portions of Retroplast-A and Retroplast-B pastes were mixed according to the manufacturer's instructions and the perforations were filled with the material.

After chemical curing, the unpolymerised surface layer of the sealing was removed with a miniature brush soaked in $96 \%$ ethanol. The pulp chamber was rinsed twice with saline.

\section{Group 5}

Dentine control. These teeth had no perforations created and filled, and the roots, except the furcation area, were completely covered with wax (see Bacterial test procedure).

\section{Group 6}

Negative control. The roots and furcation area were completely covered with wax (see Bacterial test procedure).

\section{Bacterial test procedure}

After preparation and filling procedures, the teeth of all groups were stored in gauze dampened with sterile water overnight at $37^{\circ} \mathrm{C}$ and $100 \%$ humidity. A coat of transparent nail varnish was applied to the external surface of all teeth, except the furcation area around perforations, in order to standardise the area of leakage. The bacterial leakage model consisted of an upper chamber and a lower chamber as described by Barthel et al. ${ }^{25}$

The roots of the teeth were sealed with heat-moistened sticky wax so that the furcation area around the repaired perforation was left uncovered (except Group 6).

Table 2 Dentine thickness $(\mathrm{mm})$ at the furcation area for the investigated material groups

\begin{tabular}{l|l}
\hline Experimental groups, group number & Dentine thickness $(\mathrm{mm})$ \\
\hline 1: Mineral trioxide aggregate, tooth-coloured & $2.5 \pm 0.6$ \\
\hline 2: Mineral trioxide aggregate, grey & $2.4 \pm 0.5$ \\
\hline 3: Resin-modified glass-ionomer cement & $2.2 \pm 0.6$ \\
\hline 4: Composite & $2.4 \pm 0.4$ \\
\hline 5: Dentine control & $2.5 \pm 0.4$ \\
\hline 6: Negative control & $2.4 \pm 0.7$
\end{tabular}

Then the teeth were inserted individually in $15 \mathrm{~mL}$ polycarbonate centrifuge tube with a hole prepared at the bottom, and with the region containing the perforation protruding through the end. The tube was used to create the bacterial reservoir (upper chamber). The interface between the tooth and tube was sealed with heat-moistened sticky wax. The mounts were placed in a sterile glass flask (lower chamber) containing $10 \mathrm{~mL}$ sterile tryptone soya broth (TSB; Oxoid Ltd., Basingstoke, UK) with $2 \mathrm{mg} / \mathrm{mL}$ streptomycin (Sigma-Aldrich Chemie GMBH, Steinheim, Germany) and tightly sealed with wax. The furcation areas extruding from the polycarbonate centrifuge tube were kept vertically into the broth. The upper chamber was filled with medium without bacteria on day -1 , and checked for leakage until day 0. If the amount of liquid in the lower chamber visually increased, the wax seal was considered inadequate, and the waxing procedure was repeated.

A strain (A197A) of Enteroccocus faecalis (Enter. faecalis) was grown in TSB with $2 \mathrm{mg} / \mathrm{mL}$ streptomycin and added to each upper chamber. The TSB in the upper chamber was changed twice a week to maintain viability and numbers of bacteria. The mounts were incubated at $37^{\circ} \mathrm{C}$ throughout the experiment (50 days). The bottom chambers were checked daily for turbidity in the broth as evidence for penetration of bacteria. Once turbidity was detected in the lower chamber, samples of the broth were seeded on TSB-agar plates subcultured with streptomycin. The nature and purity of the organisms growing there were confirmed by cultural morphology and streptomycin resistance. The day of leakage was recorded for each leaking sample and the number of leaking samples was recorded for each group.
Statistical analysis of bacterial leakage experiment was performed using the Kaplan-Meier test for survival analysis and pairwise comparison of groups with the Log Rank (Mantel-Cox) and Breslow (generalized Wilcoxon) tests. A p-value less than 0.05 was considered statistically significant.

\section{Observation in the scanning electron microscope (SEM)}

After leakage was determined, randomly chosen specimens from each experimental group were further observed in SEM. These specimens were immediately fixed in buffered formalin solution. Longitudinally grooves were cut in the roots on both sides using a carborundum disc, and a chisel was used to split the tooth in two halves so that the dentine-filling interface was exposed.

The specimens were dehydrated with ethanol in ascending concentrations up to absolute alcohol, after which they were critical-point-dried with liquid $\mathrm{CO}_{2}$. The specimens were then coated with a $30 \mathrm{~nm}$ thick palladium film with a Bio-Rad Sc5000 sputter coater (Fisons Instruments, Uckfield, UK) and mounted onto an SEM specimen stub.

The specimens were viewed with a Philips XL30 ESEM scanning electron microscope (Eindhoven, The Netherlands) at $9 \mathrm{kV}$ accelerating voltage. Two or three specimens from each group were inspected for the presence of bacteria. To look for passages the bacteria could penetrate, the interface between the filling material and dentine was followed from the pulp chamber to the furcation area. Photos were taken of the interface or in the close vicinity of the interface at 3000x magnification. Six photos (1-6) were taken showing the material/dentine interface and three photos 
(7-9) were taken showing the material or the surface dentine opposing the material. The SEM images were divided into areas 1 and 2, where area 1 images were closeups of the dentine/material interface (six images). Area 2 images were made either on the material or on the tooth where the material had been situated (three images).

\section{RESULTS}

\section{Bacterial leakage test}

The results of the bacterial penetration test are summarised in Figure 1. The experimental groups demonstrated bacterial leakage to varying degrees within the first 32 days. After this period, no additional samples leaked during the final 18 days of the study. The percentages of leaking samples were 29, 20, 60, and 86, for Group 1, Group 2, Group 3, and Group 4, respectively. The onset of leaking started on day 2, 3, 2, and 1 , for Groups 1-4, respectively. No statistically significant difference was detected between Groups 1-3 ( $p>0.05)$. The bacterial leakage percentage of Group 4 was significantly higher than those of the other material groups and the negative control group (Group 6) ( $p<0.05)$. Seven (54\%) of the 12 samples of the dentine group (Group 5) became contaminated, while no evidence of leakage occurred in Group 6 during the experimental period. No statistically significant relation between dentine thickness and bacterial leakage was observed. Subculturing bacteria confirmed the presence of Enter. faecalis.

\section{Scanning electron microscopy investigation}

Bacteria were observed in all leaking specimens: in the interface between filling and dentine, on the material and on the prepared areas where the material had been situated. The growth of bacteria seemed to be more sparse on the material and the site where the material had been situated. Bacteria were also observed by spot tests on the dentine surface some distance away from the prepared areas. SEM images of the longitudinal section of samples filled with resin composite showed bacteria on the dentine and material surfaces (Fig. 2).

\section{DISCUSSION}

The bacterial leakage model was chosen due to its suggested relevance for clinical

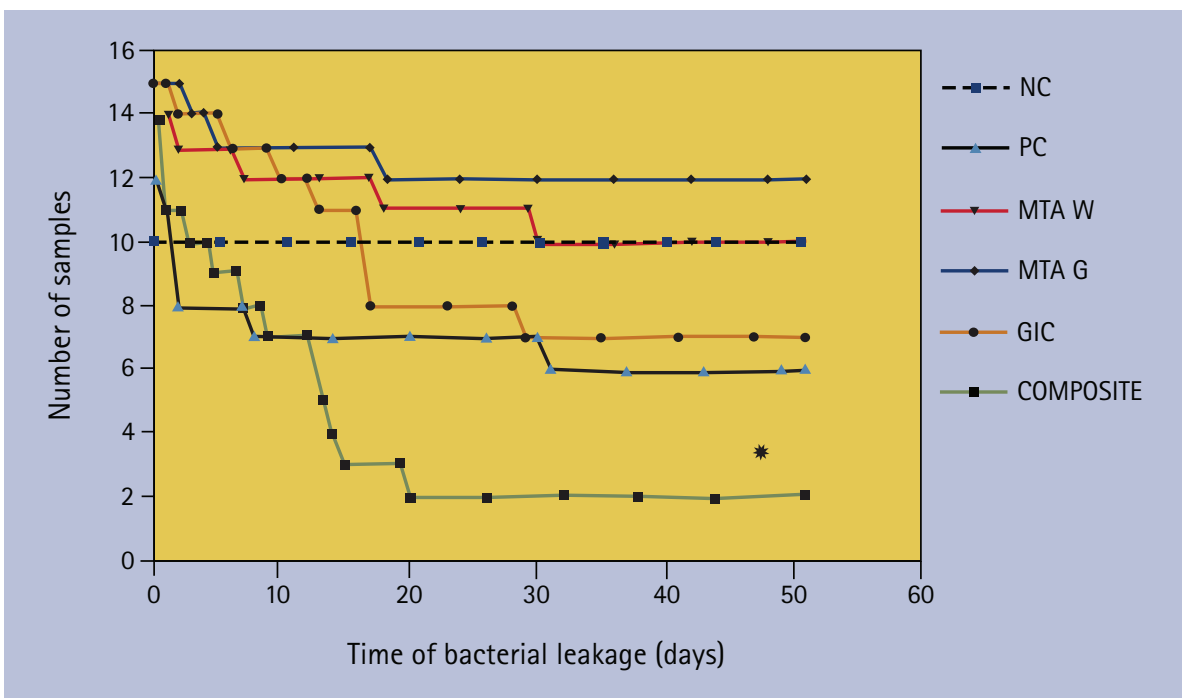

Fig. 1 Number of specimens in each material group showing resistance to leakage over a period of 50 days. MTA W: mineral trioxide aggregate, tooth-coloured $(n=14)$; MTA G: mineral trioxide aggregate, grey $(n=15)$; GIC: resin-modified glass ionomer cement $(n=15)$; COMPOSITE: resin composite $(n=15)$; NC: negative control group $(n=10)$; PC: positive control/dentine group $(n=12) ;{ }^{*}$ denotes significant difference in bacterial leakage percentage compared to the other material groups and NC $(p<0.05)$

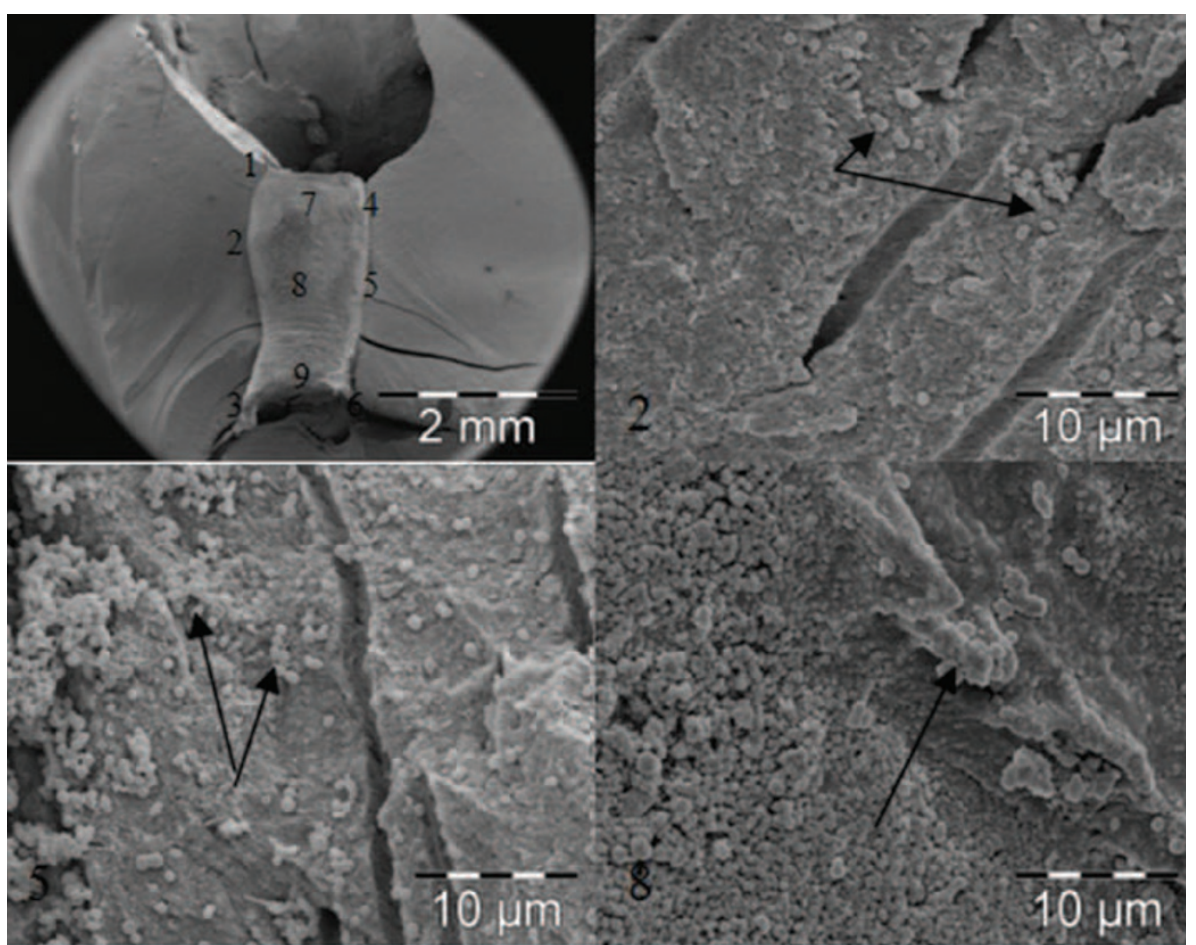

Fig. 2 Scanning electron microscopy images of longitudinal sections of samples filled with resin composite. Bacteria (black arrows) were observed on the dentine (sites 2 and 5) and material surface (site 8)

situations, ${ }^{26}$ although this relevance has been questioned. Wu \& Wesselink ${ }^{27}$ assessed the methodology of leakage studies and questioned their application and relevance. They concluded that the variations between the leakage experiments made it difficult to compare the results. They also suggested that great variation of the specimen within each study made it difficult to standardise the results. In spite of this view we found the method feasible for comparing various materials and tracking bacteria.

The test tracers in leakage tests should be representative of bacteria and their byproducts since they are the main cause of endodontic failure. Most dyes are of smaller molecular size and will therefore more easily penetrate the material/dentine interfaces, cracks and crevices. Kersten and 
Moorer ${ }^{28}$ investigated leakage relative to particles of different molecular size. These particles, common to bacteria and their by-products, were compared with dyes. The authors found that leakage of bacteria-sized particles and large-sized protein molecules could be prevented when both sealer and pressure were used in obturating root canals with gutta percha. Prevention of leakage of small molecules was independent of the method used. Therefore, it was suggested that leakage tests with low molecular weight materials may be of doubtful significance.

In the present study, the samples in the negative control group did not leak for the experimental duration of 50 days. In contrast, some of the dentine group developed turbidity in the lower chamber within 32 days of inoculation. In most instances the pathway of contamination is suggested to occur along the material/ dentine interface, but our results indicate that penetration may also occur through dentinal tubules or furcation canals. In the root canal morphology studies of Vertucci $^{29}$ it was found that $10-11 \%$ of mandibular molars and 18-23\% of maxillary molars harbour furcation canals. Haapasalo and Ørstavik ${ }^{30}$ found that bacteria could penetrate up to $300-400 \mu \mathrm{m}$ into the dentinal tubules in one day and at least $800-1000 \mu \mathrm{m}$ in three weeks.

The bacterial leakage method was used employing the facultative anaerobic bacteria Enter. faecalis as a microbial tracer for evaluating the sealing ability of furcation perforation repair materials. The leakage of bacteria into periapical tissues is claimed to be the major cause of periradicular pathosis. Furthermore, the majority of bacteria associated with infections of endodontic origin are strict anaerobes. Therefore, the detection of anaerobic bacteria is a more clinically relevant demonstration of microleakage associated with an endodontic filling material. ${ }^{15}$ Microbiological studies have shown that in failed endodontic therapy the most commonly recovered isolates were from Enter. faecalis. ${ }^{31,32}$

In the present study, most bacterial leakage was observed in the resin composite group. This fact might be explained by the flow properties and contraction of composite resin that may pull the material away from the cavity walls, resulting in gaps. One may speculate that the increased leakage was due to the "Adper" Scotchbond multi-purpose adhesive system that was used as dentine bonding agent instead of GLUMA ${ }^{\circledR}$ Desensitizer (Heraeus Kulzer G.m.b.H., Wertheim, Germany), which was recommended by the manufacturer.

The good sealing ability of MTA in repairing furcation perforations is well documented..$^{33,34}$ In the present study, there was no difference in percentage leakage between tooth-coloured and grey MTA-groups. This finding is consistent with previous studies where dye extraction or the bacterial leakage model was used to evaluate leakage. ${ }^{15,35}$ According to Torabinejad et al., ${ }^{12}$ the relatively low bacterial leakage observed when MTA was used as repair material was a result of its sealing ability rather than any antimicrobial properties of the material. Several studies have shown that MTA does not have any significant growth inhibiting effect on a number of oral bacteria. ${ }^{36,37}$ In contrast to these findings, Eldeniz et al., ${ }^{38}$ evaluating the antibacterial activity of leachable components from selected rootend filling materials, found that set samples of ProRoot MTA cement completely inhibited Pseudomonas aeruginosa and delayed or limited growth of Enter. faecalis. Similar results were obtained in other studies where the antimicrobial properties of MTA were evaluated. . $^{39,40}$

Glass-ionomer cement was found to be superior compared with composite resin, amalgam, temporary dental restorative material (Cavit W) and tricalcium phosphate when used in furcation perforation repair in previous studies. ${ }^{2,6,8,19,41}$ However, when the MTA cement was introduced, it showed increased resistance to leakage in furcal perforations compared with glass-ionomer cement. ${ }^{9,23}$ A similar trend was seen in the present study, but the difference between the MTAs and the glass ionomer cements was not statistically significant. Spot tests with SEM revealed bacteria in dentine a distance away from the prepared areas in all specimens. In the dentine controls, the dentinal tubules were the most likely pathways for bacteria since these specimens were not perforated in the furcation area and wax was sealed around the entire root, except in the furcation area. This observation indicates that bacteria not only follow the passages between the material and dentine interfaces, but may also move via the dentine tubules independently of the material/dentine passageway. Hence, it is possible that leakage due to dentine penetration contributed to the overall observed leakage. Another possible contribution to the observed leakage is through furcation canals..$^{29,42}$ Thus, the antibacterial effect may be important as addressed in several studies. ${ }^{12,38}$ The specimens showed leakage by turbidity in the TSB-broth in the lower chamber, which means that bacteria had moved from the pulp chamber. However, the potential antibacterial effect of the material may have killed bacteria that were penetrating close to the material surface. Hence, we speculate that the turbidity observed may also be a result of bacterial movement through the dentinal tubules rather than alongside the material. Evidence of antibacterial effects could not be ascertained as the SEM images cannot be used to discriminate between vital and dead bacteria.

Bacterial penetration through intact dentine was an interesting observation, which underscores the complexities of leakage experiments in endodontics. The pilot nature of this part of the study precludes statistical analysis and firm conclusions, but the findings warrant further investigations.

\section{CONCLUSION}

There was significantly greater leakage of resin composite perforation repair fillings compared to mineral trioxide aggregate and glass ionomer cement. Bacterial contamination may occur through furcation canals or dentinal tubules as well as along the material-dentine interface.

The authors would like to thank Mr S. Stølen (Institute of Oral Biology, University of Oslo, Norway) for his help with the scanning electron microscopy, Ms I. S. Dragland (NIOM, Haslum, Norway) for laboratory assistance, Ms I. Nedzelskiene (Department of Dental and Oral Pathology, Kaunas University of Medicine, Lithuania) for statistical assistance, and local suppliers for materials.

1. Fuss Z, Trope M. Root perforations: classification and treatment choices based on prognostic factors. Endod Dent Traumatol 1996: 12: 255-264.

2. Tsatsas D V, Meliou H A, Kerezoudis N P. Sealing effectiveness of materials used in furcation perforation in vitro. Int Dent J 2005; 55: 133-141.

3. Simon J H, Glick D H, Frank A L. The relationship of endodontic-periodontic lesions. J Periodontol 1972; 43: 202-208.

4. Petersson K, Hasselgren G, Tronstad L. Endodontic treatment of experimental root perforations in dog teeth. Endod Dent Traumatol 1985; 1: 22-28.

5. Kvinnsland I, Oswald R J, Halse A, Gronningsaeter A G. A clinical and roentgenological study of 55 
cases of root perforation. Int Endod J 1989; 22: 75-84.

6. Alhadainy H A, Himel V T. Comparative study of the sealing ability of light-cured versus chemically cured materials placed into furcation perforations. Oral Surg Oral Med Oral Pathol 1993; 76: 338-342.

7. Rud J, Rud V, Munksgaard E C. Retrograde sealing of accidental root perforations with dentin-bonded composite resin. J Endod 1998; 24: 671-677.

8. Alhadainy H A, Himel V T. Evaluation of the sealing ability of amalgam, Cavit, and glass ionomer cement in the repair of furcation perforations. Oral Surg Oral Med Oral Pathol 1993; 75: 362-366.

9. Krupalini K S, Udayakumar, Jayalakshmi K B. A comparative evaluation of medicated calcium sulphate, hydroxylapatite, mineral trioxide aggregate (MTA) as barrier and their effect on the sealing ability of furcation perforation repair material-an in vitro study. Indian J Dent Res 2003; 14: 156-161.

10. De Bruyne M, De Moor R. The use of glass ionomer cements in both conventional and surgical endodontics. Int Endod J 2004; 38: 129-136.

11. Maher W P, Johnson R L, Hess J, Steiman H R. Biocompatibility of retrograde filling materials in the ferret canine. Amalgam and IRM. Oral Surg Oral Med Oral Pathol 1992; 73: 738-745.

12. Torabinejad M, Hong C U, Pitt Ford T R, Kettering J. Antibacterial effects of some root end filling materials. J Endod 1995; 21: 403-406.

13. Asgary S, Parirokh M, Eghbal M J, Brink F. Chemical differences between white and gray mineral trioxide aggregate. J Endod 2005; 31: 101-103.

14. Camilleri J, Montesin F E, Brady K, Sweeney R, Curtis $R V$, Ford T R. The constitution of mineral trioxide aggregate. Dent Mater 2005; 21: 297-303.

15. Ferris D M, Baumgartner J C. Perforation repair comparing two types of mineral trioxide aggregate. J Endod 2004; 30: 422-424.

16. Main C, Mirzayan N, Shabahang S, Torabinejad M. Repair of root perforations using mineral trioxide aggregate: a long-term study. J Endod 2004; 30: 80-83.

17. Breault $L$ G, Fowler E B, Primack P D. Endodontic perforation repair with resin-ionomer: a case report. J Contemp Dent Pract 2000; 15: 48-59.

18. Alhadainy H A, Abdalla A I. Artificial floor technique used for the repair of furcation perforations: a microleakage study. J Endod 1998; 24: 33-35.

19. Himel V T, Alhadainy H A. Effect of dentin preparation and acid etching on the sealing ability of glass ionomer and composite resin when used to repair furcation perforations over plaster of Paris barriers. J Endod 1995; 21: 142-145.

20. Alhadainy $H A$, Himel V T. An in vitro evaluation of plaster of Paris barriers used under amalgam and glass ionomer to repair furcation perforations. J Endod 1994; 20: 449-452.

21. Shuman IE. Repair of a root perforation with a resin-ionomer using an intentional replantation technique. Gen Dent 1999; 47: 392-395.

22. Behnia A, Strassler H E, Campbell R. Repairing iatrogenic root perforations. J Am Dent Assoc 2000; 131: 196-201.

23. Daoudi M F, Saunders W P. In vitro evaluation of furcal perforation repair using mineral trioxide aggregate or resin modified glass lonomer cement with and without the use of the operating microscope. J Endod 2002; 28: 512-515.

24. Tsesis I, Fuss Z. Diagnosis and treatment of accidental root perforations. Endod Topics 2006; 13: 95-107.

25. Barthel C R, Moshonov J, Shuping G, Orstavik D. Bacterial leakage versus dye leakage in obturated root canals. Int Endod J 1999; 32: 370-375.

26. Torabinejad M, Ung B, Kettering J D. In vitro bacteria penetration of coronally unsealed endodontically treated teeth. J Endod 1990; 16: 566-569.

27. Wu M K, Wesselink P R. Endodontic leakage studies reconsidered. Part I. Methodology, application and relevance. Int Endod J 1993; 26: 37-43.

28. Kersten H W, Moorer W R. Particles and molecules in endodontic leakage. Int Endod J 1989; 22: $118-124$.

29. Vertucci F. Root canal morphology and its relationship to endodontic procedures. Endod Topics 2005; 10: 3-29.

30. Haapasalo $M$, Orstavik D. In vitro infection and disinfection of dentinal tubules. J Dent Res 1987; 66: $1375-1379$

31. Sundqvist $G$, Figdor D, Persson S, Sjogren U. Microbiologic analysis of teeth with failed endodontic treatment and the outcome of conservative re-treatment. Oral Surg Oral Med Oral Pathol Oral Radiol Endod 1998; 85: 86-93.

32. Peciuliene $\mathrm{V}$, Balciuniene I, Eriksen $\mathrm{H}$ M, Haapasalo M. Isolation of Enterococcus faecalis in previously root-filled canals in a Lithuanian population. J Endod 2000; 26: 593-595.

33. Weldon J K, Jr., Pashley D H, Loushine R J, Weller $R N$, Kimbrough W F. Sealing ability of mineral trioxide aggregate and super-EBA when used as furcation repair materials: a longitudinal study. J Endod 2002; 28: 467-470.

34. Tsai $Y L$, Lan W H, Jeng J H. Treatment of pulp floor and stripping perforation by mineral trioxide aggregate. $J$ Formos Med Assoc 2006; 105: 522-526.

35. Hamad H A, Tordik P A, McClanahan S B. Furcation perforation repair comparing gray and white MTA: a dye extraction study. J Endod 2006; 32: 337-340.

36. Miyagak D C, de Carvalho E M, Robazza C R, Chavasco J K, Levorato $G \mathrm{~L}$. In vitro evaluation of the antimicrobial activity of endodontic sealers. Braz Oral Res 2006; 20: 303-306.

37. Yasuda Y, Kamaguchi A, Saito T. In vitro evaluation of the antimicrobial activity of a new resin-based endodontic sealer against endodontic pathogens. J Oral Sci 2008; 50: 309-313.

38. Eldeniz A U, Hadimli H H, Ataoglu H, Orstavik D. Antibacterial effect of selected root-end filling materials. J Endod 2006; 32: 345-349.

39. Sipert C R, Hussne R P, Nishiyama C K, Torres $S$ A. In vitro antimicrobial activity of Fill Canal, Sealapex, Mineral Trioxide Aggregate, Portland cement and EndoRez. Int Endod J 2005; 38: 539-543.

40. Tanomaru-Filho M, Tanomaru J M, Barros D B, Watanabe $E_{\text {, I }}$ to I Y. In vitro antimicrobial activity of endodontic sealers, MTA-based cements and Portland cement. J Oral Sci 2007; 49: 41-45.

41. Fuss Z, Abramovitz I, Metzger Z. Sealing furcation perforations with silver glass ionomer cement: an in vitro evaluation. J Endod 2000; 26: 466-468.

42. Haznedaroglu F, Ersev H, Odabasi H, Yetkin G, Batur $B$, Asci $S$ et al. Incidence of patent furcal accessory canals in permanent molars of a Turkish population. Int Endod J 2003; 36: 515-519. 